\title{
Educação especial no território federal de Roraima no contexto do regime militar (1964-1985)
}

\author{
MARIA EDITH ROMANO SIEMS-MARCONDES \\ Universidade Federal de Roraima, Boa Vista, RR, Brasil
}

RESUMO

Este texto apresenta aspectos da trajetória histórica de implantação da educação especial no território federal de Roraima em sua gênese, em meados de 1970 até 1990. Fundamentado nos pressupostos do materialismo histórico-dialético, adota como eixo central a perspectiva desenvolvida por E. P. Thompson de uma análise histórica que tome por referência a experiência dos sujeitos, uma "história vista de baixo". Apoia-se em entrevistas com professores e técnicos atuantes na área, bem como na análise de documentos produzidos no cotidiano das instituições. Evidencia como Roraima, assumida como área de segurança nacional, sob a tutela das Forças Armadas, sem ações colocadas em prática anteriormente, foi campo de aplicação das políticas e propostas prioritárias da reforma educacional projetada pelo regime militar em âmbito nacional, mantidos todos os serviços sob financiamento e gerenciamento do poder público, sem a presença de instituições não governamentais, beneficentes ou filantrópicas.

\section{PALAVRAS-CHAVE}

educação especial; história da educação; história da educação especial; excepcionais; história de Roraima. 
SPECIAL EDUCATION IN FEDERAL TERRITORY OF RORAIMA IN THE CONTEXT OF THE MILITARY GOVERNMENT (1964-1985)

\begin{abstract}
This paper traces the historical trajectory of special education in the federal territory of Roraima from its inception in the mid-1970s to 1990. The ideas developed in this study were grounded within the dialectical materialist framework and exemplified by E. P. Thompson's historical analysis of the experience of the subject, a "history from the bottom up". Data are collected in state of Roraima, using interviews with teachers and technicians involved in the field and in the analysis of documents produced in the daily life of institutions. Under the tutelage of the armed forces, programs were designed and managed financially without participation of non-governmental, charitable or philanthropic institutions. These findings underscore the importance of both governmental and non-governmental agencies contributions to special education as well as developing strategies to tackle the problems of special needs.
\end{abstract}

\title{
KEYWORDS
}

special education; education history; special education history; special needs student; Roraima's history.

\section{EDUCACIÓN ESPECIAL EN EL TERRITORIO FEDERAL DE RORAIMA EN EL CONTEXTO DEL RÉGIMEN MILITAR (1964-1985)}

\section{RESUMEN}

Este artículo presenta la trayectoria histórica de la implementación de la educación especial en el territorio federal de Roraima desde su génesis a mediados de la década de 1970 hasta 1990. Sobre la base de los supuestos del materialismo histórico y dialéctico, como eje central adopta la perspectiva desarrollada por E.P.Thompson un análisis histórico que hacen referencia a la experiencia del sujeto, una "historia desde abajo". Se basa en entrevistas con los profesores y los técnicos involucrados en el campo y en el análisis de los documentos que se producen en la vida cotidiana de las instituciones. Evidencia de que Roraima, asumido como área de seguridad nacional, bajo la tutela de las fuerzas armadas, sin acciones ejecutadas anteriormente, fue el alcance de las políticas y prioridades de las propuestas de reforma de la educación diseñadas por el régimen militar en el ámbito nacional, el mantenimiento de todos los servicios bajo la financiación y la gestión del poder público.

\section{PALABRAS CLAVE}

educación especial; historia de la educación; historia de la educación especial; excepcional; historia de Roraima. 
Roraima ocupa a posição mais setentrional do território brasileiro. Parte de seu espaço localiza-se no hemisfério norte e vivenciou um processo tardio de ocupação ${ }^{1}$ por populações não indígenas entre os séculos XVII e XIX, em face de suas peculiaridades climáticas e dificuldades de acesso.

$\mathrm{Na}$ década de 1970, o governo federal, conduzido por dirigentes militares em suas políticas de defesa das fronteiras em nome da Segurança Nacional e da lógica de integrar para não entregar, estabelece políticas de incentivo à migração para os territórios federais e finaliza a construção de acessos por via terrestre à capital.

No atendimento educacional da população que para Roraima migra em busca de terra, minérios e oportunidades de crescimento pessoal e profissional, a educação especial inicia-se em 1976 como ação governamental custeada e gerida com recursos públicos no âmbito dos sistemas educacionais. Esse processo contrapõe-se às ações assistencialistas de natureza filantrópica e privada que, na ausência formal do Estado, expandia-se como base das ações destinadas às pessoas com deficiência no Brasil.

Ao buscar compreender como se dá a implantação desses serviços educacionais no estado de Roraima, as razões que levaram o poder público a incorporá-los entre suas ações e possíveis implicações decorrentes do fato de esse atendimento ser, desde a sua origem, parte da oferta nos espaços públicos de ensino, deparamo-nos com o fato de que, na ausência de ações e serviços públicos ou privados destinados às pessoas com deficiências no período anterior a 1970, as ações implantadas no então território federal de Roraima trouxeram as marcas de se desenvolverem como aplicação direta dos planos e metas previstos nas políticas do poder central, em especial nas políticas do órgão gestor da educação especial da época, o Centro Nacional de Educação Especial (CENESP).

Trata-se de um estudo em história da educação que parte da história da educação especial no território federal de Roraima, mas que evidencia que esta se dá como parte das políticas e propostas da reforma educacional estabelecida durante o período do regime militar que conduziu o Brasil na segunda metade do século XX. Abarca o período de 1973 a 1990 (ano em que se efetiva a transformação do território em estado, com a posse dos primeiros dirigentes eleitos, e se encerra a direta intervenção do governo central).

A delimitação desse período decorre de ser esse o momento em que se dá a gênese dos serviços em Roraima, afinada com o forte movimento que impacta a área na época. Na afirmação de Bueno (2004, p. 34) para a educação especial, "o período privilegiado será a década de 1970, quando esta se constituiu efetivamente como subsistema educacional". Também Jannuzzi (1985, p. 196) indica que "podemos colocar a década de 1970 como um marco divisor da EE, porque até então ela esteve mais sujeita à sensibilidade das associações, principalmente filantrópicas".

O trabalho de pesquisa foi construído na perspectiva do materialismo histórico-dialético e utiliza como referencial teórico-metodológico os estudos do historiador inglês Edward Palmer Thompson em sua perspectiva conceitual de uma história "vista de baixo" assumindo, em decorrência disso, o desafio de compreender

1 Para maior aprofundamento do sentido de "ocupação" em Roraima, ver Santos (2004). 
esse processo a partir de como se deu a vivência dos processos na ótica de atores que participaram ativamente da implantação e desenvolvimento das estruturas sociais e educacionais.

Mas "olhar de baixo" a história da educação especial seria o quê? No entendimento que fomos construindo ao longo do percurso de pesquisa, o "olhar de baixo" a história da educação especial em nosso contexto se traduziria no trazer à baila a voz dos atores que viveram diretamente esses serviços e os documentos por eles produzidos no cotidiano de suas atividades profissionais.

Estudos tradicionais da área da história da educação especial no Brasil, como os de Mazzotta (2001) e Jannuzzi (2004), tomam por base os documentos oficiais, a história das instituições de maior projeção e os dirigentes que se destacam com suas ações. São pouco presentes nesses registros as vivências dos professores, dos alunos egressos desses espaços e de seus familiares.

Nesse sentido, optamos por trilhar um caminho em que pudéssemos trazer a voz dos professores, dos técnicos e de pais de alunos que viveram como experiência ${ }^{2}$ as práticas realizadas nos serviços disponibilizados para a educação de pessoas com deficiência em Roraima.

Alertamos que, ao assumir o desafio de trazer à cena a voz desses atores, não estamos colocando-nos na lógica de desenvolver um trabalho no âmbito da história oral, já que buscamos também tomar como contorno na construção dos retratos desses personagens o cotejamento de informações que pudemos acessar em documentos oficiais e demais fontes de informação que nos possibilitaram observar o painel das vivencias cotidianas da instituição. Nos documentos analisados, os que se mostraram com maior riqueza de elementos foram os de rotina institucional, como relatórios setoriais, atas de reunião, memorandos e ofícios, convites, planilhas e demais instrumentos produzidos no interior das unidades e setores, elaborados por técnicos e professores em atuação direta com os alunos e seus familiares.

O eixo central dos quais se puxam os fios da memória, entretanto, dá-se nos registros memorizados pelos entrevistados que, cotejados com esses documentos e outros que estabeleciam a normatização das políticas de educação especial da época, oportunizaram-nos um rico painel de análise e reflexão.

Estamos cientes da seletividade da memória ${ }^{3}$ e, em vários momentos das entrevistas, deparamo-nos com relatos controversos entre os dezesseis participantes

2 Como destaca Thompson (1981, p. 189): “as pessoas não experimentam sua própria experiência apenas como ideias, no âmbito do pensamento e de seus procedimentos, ou (como supõem alguns praticantes teóricos) como instinto proletário, etc. Elas também experimentam sua experiência como sentimento e lidam com esses sentimentos na cultura, como normas, obrigações familiares e de parentesco, e reciprocidades, como valores ou (através de formas mais elaboradas) na arte ou nas conviç̧ões religiosas".

3 "Cabe refletir aqui que a memória é, hoje, referência muito importante para a luta pelos direitos civis, é compreendida como atributo constituinte da cidadania, é valorizada na formação de identidades culturais dos diferentes grupos sociais. Há, nessa revitalização da memória, uma explícita positividade política e a percepção de que a memória é a atualização do passado, ao mesmo tempo em que é a aceitação dos traços do passado no presente, da memória como sinônimo da vida” (Kaufmann; Martins, 2009, p. 258-259). 
de entrevistas ou incompatíveis com elementos concretos indicados por fontes documentais. Porém, no tratamento dos dados, buscamos assumir o pressuposto da relevância da experiência como vivida pelos sujeitos e registrada em suas memórias.

A realização de uma pesquisa que toma como foco de análise uma perspectiva regional, com foco em uma localidade distante dos eixos de decisão do governo federal, parte da ideia de que, sendo o Brasil um país de dimensões continentais, com diversidade expressiva na constituição de seus grupos sociais, os impactos das políticas públicas nacionais e as relações estabelecidas entre diversos grupos culturais apresentam marcas próprias. Bastos $(2009$, p. 69) assim se refere aos estudos regionais:

Para a história da educação, os estudos na perspectiva de uma história local intentam pontuar a diversidade de apropriações dos discursos e das práticas educativas e escolares, de acordo com as particularidades de tempo e espaço e as implicações econômico-socioculturais de cada lócus pesquisado.

Fomos movidos pela fala de Faria Filho (2009, p. 62) de que "nenhum ser humano realiza a sua humanidade na generalidade do universal, mas sim na particularidade de sua experiência numa região determinada”. Estamos aqui tomando o espaço da região não apenas "no sentido geográfico do termo, mas como espaço vivido, como um sistema de relações, como referência identitária" (Bastos, 2009, p. 68).

Nesse sentido, ao nos propormos a olhar elementos do desenvolvimento da história da educação especial em uma localidade pouco conhecida na porção mais populosa do país, em um período politicamente conturbado, encontramos dados que possibilitam um olhar diversificado no sentido de se compreender elementos da educação especial brasileira em sentido mais amplo.

\section{A EDUCAÇÃO ESPECIAL NO BRASIL}

Em 1961, a lei de Diretrizes e Bases da Educação Nacional n. 4.024 de 1961 traz a educação dos excepcionais à baila em seus artigos 88 e 89 , indicando que esta deverá "no que for possível, enquadrar-se no sistema geral de educação, a fim de integrá-los [o aluno deficiente] na comunidade". É, entretanto, dúbia, ao indicar no artigo 30, inciso d, que não há a obrigatoriedade de matrículas quando da apresentação de "doença ou anomalia grave da criança".

No processo de reforma do ensino pretendido pelo regime militar, em 1971, a lei federal n. 5.692, sancionada em 11 de agosto, traz oficialmente ao universo da educação no âmbito de políticas públicas as pessoas com deficiência como população-alvo das ações governamentais. Em seu artigo $9^{\circ}$, indica que:

Os alunos que apresentam deficiências físicas ou mentais, os que se encontrem em atraso considerável quanto à idade regular de matrícula e os superdotados deverão receber tratamento especial, de acordo com as normas fixadas pelos competentes Conselhos de Educação. 
O olhar do regime militar já havia dado sinais de seu direcionamento à questão do atendimento às pessoas com deficiência. Um dos indicativos dessa preocupação que encontramos em nosso processo de pesquisa foi o decreto federal n. 54.188, assinado pelo presidente Humberto de Alencar Castello Branco, de 28 de agosto de 1964, que instituiu a Semana Nacional da Criança Excepcional a ser comemorada anualmente, segundo a determinação legal, de 21 a 28 de agosto, em todo o território nacional.

Esse decreto delega ao ministro da Educação e Cultura a responsabilidade de expedir as instruções a todos os órgãos vinculados ao ministério, para que se "dê maior relevo" a essa semana que, como veremos mais adiante, será parte expressiva das ações da equipe da educação especial em Roraima.

Em 1971, o Ministério da Educação e Cultura (MEC) institui um grupo tarefa com a determinação de avaliar o estado da educação especial no país, assumindo essa área como prioritária no I Plano Setorial de Educação. A lei federal n. 5.692 de 1971 e o parecer do Conselho Federal de Educação (CFE), n. 848/1972, enfatizam a necessidade de que sejam implantados serviços especializados nos sistemas de ensino, o que culminará na criação, por meio do decreto n. 72.425/1973, do CENESP, órgão destinado à coordenação das ações da política educacional para os então chamados excepcionais.

Ao discutir a "simbiose entre o público e o privado" que marca o campo da educação especial, atendido prioritariamente por instituições filantrópicas ou assistenciais, a exemplo da nacionalmente reconhecida Associação de Pais e Amigos dos Excepcionais (APAE) e do Instituto e Sociedade Pestalozzi, Jannuzzi (2004, p. 188-189) analisa que, "de 1959 a 1989 o setor público só arcou com a responsabilidade de 20 a $25 \%$ desse setor".

No caso específico de Roraima, não registramos a existência de instituições privadas especializadas em educação especial ou com características de assistência/ filantropia. Os serviços são, desde seu nascimento, atrelados aos sistemas de educação - e não de assistência social ou saúde -, além de serem integralmente custeados com recursos públicos e gerenciados por unidades setoriais dentro das secretarias de educação.

Também em âmbito mundial crescia o direcionamento dos olhares sobre as pessoas com deficiência. Especificamente em relação às pessoas com deficiência mental, a Organização das Nações Unidas (ONU), em assembleia geral, realizada em 30 de dezembro de 1971, aprovou a Declaração dos Direitos do Deficiente Mental. Essa declaração apresenta direitos entendidos como fundamentais a serem assegurados às pessoas que nomina como "mentalmente retardadas", pedindo que se adotem nacional e internacionalmente as medidas necessárias para que estes sejam alcançados. Entre elas destaca o direito à "educação, à capacitação, à reabilitação e à orientação que lhe permitam desenvolver ao máximo sua capacidade e suas aptidões". Salienta ainda a importância de que essa população tenha acesso aos demais direitos sociais, o que evidentemente incluiria o acesso à escola pública.

Jannuzzi (2004, p. 140-141), ao tratar da presença da educação especial ao longo do regime militar, destaca que o presidente Médici (1969-1974) utiliza em mensagem ao Congresso o título educação especial. Salienta ainda a existência de 
uma “pressão legal” que levou à aprovação do parecer CFE n. 848/1972 em resposta a uma determinação ministerial que vem acompanhada de carta do presidente das APAEs cobrando providências relativas ao "ensino e amparo ao excepcional".

São ações que conduzirão ao processo que gerou não só a inserção do tema em nossa legislação federal, mas a criação, em 1973, do CENESP no interior do MEC. Nesse contexto de pressões, segundo Pires (1974, p. 19),

O Brasil vai engajar-se no esforço de pesquisa, experimentação e ação que se desenvolve no mundo, buscando soluções que possibilitem aos excepcionais, segundo as condições de cada um, viverem plena e condignamente como pessoas e cidadãos.

Assumindo essa demanda como um projeto prioritário do Plano Setorial de Educação e Cultura, para o período 1973/1974, o MEC constituiu, entre julho de 1972 e fevereiro de 1973, um grupo tarefa para operacionalizá-lo, sob a direção da professora Nise Pires. Assim, Pires (1974, p. 21), que já havia integrado o Grupo de Trabalho que elaborou a Reforma do Ensino de $1^{\circ}$ e $2^{\circ}$ Graus, refere-se a esse processo:

Constituiu-se um grupo tarefa, formado por elementos do Instituto Nacional de Estudos e Pesquisas (INEP) e representantes do então Departamento de Ensino Complementar (DEC) e da Secretaria Geral do MEC. Assessorado por ampla consultoria de especializações diversificadas, mas tendo em comum alto gabarito técnico, o grupo tarefa empreendeu a montagem do Projeto Prioritário n. 35 .

Esse trabalho constituiu um dos fundamentos para a criação do CENESP, por meio do decreto n. 72.425 de 3 de julho de 1973, com o objetivo de promover a melhoria do atendimento aos excepcionais, deficientes e superdotados. Esse órgão vai assumir como diretrizes básicas orientadoras das políticas de educação especial no país a integração e a racionalização.

No planejamento de suas ações prevê para o período 1974 a 1978 a "programação do apoio técnico à educação especial” investindo para tal na formação de recursos humanos e na criação e aperfeiçoamento de "instrumentos de apoio técnico para a educação especial” e, a partir de 1979, após a constituição dessa estrutura que iria assegurar a qualidade das ações, "será priorizada a expansão quantitativa da educação especial” (Pires, 1974, p. 41).

Nesse processo de formação de recursos humanos, Jannuzzi (2004) e Mazzotta (2001) destacam a ocorrência não só de cursos oferecidos no país aos gestores e técnicos do órgão central e das secretarias estaduais, mas a liberação de bolsas de estudo para a formação de mestres e doutores em universidades estrangeiras. É a perspectiva de formação de um corpo técnico de excelência que se instaura.

O CENESP passa a ter atuação destacada, em especial nos territórios federais, o caso de Roraima. No estudo do impacto dessas políticas em Roraima, vários foram os depoimentos de professores que a esse órgão se referiram. 
Nos anos iniciais de instalação da educação especial em Roraima, os professores eram também os profissionais que viriam a tornar-se gestores dos serviços, tendo essa participação em processos formativos capitaneados pelo CENESP. Nos anos posteriores, com a expansão do volume de profissionais, observa-se uma redução do acesso de cursos de formação para os professores. No entendimento de Mazzota (2001, p. 100-101):

Esta concentração de recursos financeiros na realização de cursos de formação de alto nível para técnicos dos órgãos centrais pode ser interpretada como evidência da centralização do poder de normatização e execução além de um sentido de "premiação" dos supostos líderes nacionais e regionais da educação especial [...]. Neste sentido, pode estar aí implícita uma abordagem do atendimento a excepcionais que, mais do que a educação escolar, privilegia a assistência e/ou reabilitação onde é primária a importância do técnico e secundária a do docente. Tal atuação parece estar perfeitamente coerente com a ação governamental geral do período, sob o governo autoritário, portanto, de centralização do poder.

O poder que vinha sendo conquistado pelas instâncias que nacionalmente se estruturavam para a coordenação das ações voltadas à educação dos excepcionais é reafirmado em entrevista com a professora Maria Mirna Souto Maior Sarah, que salienta uma questão percebida pelos técnicos que atuavam diretamente na rede como um indicativo da complexidade de relações que envolviam a área, relatando que, nos primeiros anos da implantação da capital federal em Brasília, nem todos os servidores viam com bons olhos a sua transferência da cidade do Rio de Janeiro para o Planalto Central. Resistências estabeleceram-se em alguns órgãos que, em decorrência de seu maior ou menor poder, protelaram a permanência de suas atividades na cidade do Rio de Janeiro.

A professora Mirna destaca ser esse o caso da educação especial, que apenas na década de 1980 tem sua equipe dirigente transferida para Brasília, permanecendo, ao longo dos anos de 1970, com suas instâncias decisórias no Rio de Janeiro, próximo às sedes do Instituto Nacional de Educação de Surdos (INES) e do Instituto Benjamin Constant (IBC).

Essa informação é referendada por Jannuzzi (2004) e Mazzotta (2001), quando afirmam que o CENESP, embora sempre vinculado ao MEC, manteve sua sede na cidade do Rio de Janeiro e apenas em 1986 o órgão gestor da educação especial, aquela altura já não mais o CENESP, mas a recém-criada Secretaria de Educação Especial, é transferido do Rio de Janeiro para Brasília.

Em um território federal, como era o caso de Roraima, a realidade vivida era de uma conjuntura de profunda intervenção tanto daquele quanto de outros órgãos federais. Temos o registro feito pela professora Maria Antonia Melo Cabral da forma como se dá a implantação de processos formais de planejamento no âmbito do governo territorial. Em suas memórias, registra que, por volta de 1973, a Superintendência do Desenvolvimento da Amazônia (SUDAM) oferece um curso para formação de pessoal nessa área: 
A SUDAM deu um curso para formar uma equipe de planejamento. [...] Depois desse treinamento, a gente compôs a equipe de planejamento da Secretaria. Então, na época [...], eu já tinha saído da Supervisão e já estava no Planejamento; foi quando implantou a Coordenadoria de Planejamento na Secretaria de Educação.

Nesse mesmo sentido, e coerente com as práticas pedagógicas que Saviani (2010, p. 13) qualifica como tecnicistas que se disseminavam pelo país, de busca de um controle técnico dos processos realizados, há o registro da realização de outras ações do MEC no intuito de colocar em prática sistemas de acompanhamento e controle a serem nacionalmente padronizados. Decorrentes deles, a implantação de um setor de estatística na Secretaria da Educação do Território Federal de Roraima.

Essas ações de planejamento e de controle de dados estatísticos instaladas nessa secretaria de educação puderam ser percebidas em nosso processo de pesquisa: são dos anos 1970 os primeiros documentos com dados censitários que nos foi possível localizar. Essas ações afinam-se "aos princípios racionalistas e técnicos adotados pelo regime, na reformulação ampla e sistêmica da educação" próprias do "grupo militar dirigente" (Kaufmann; Martins, 2009, p. 246). Em suas memórias referentes aos processos educacionais vivenciados no território federal nesse período, o professor Laymerie Ramos (2007, p. 15) assim se refere:

Vivíamos sob a égide do golpe militar de 1964 e, apesar da relativa liberdade que tínhamos, os "pacotes" eram mais ou menos obrigatórios. A maior parte dos programas e dos materiais didáticos vinha pronta do Ministério da Educação. O planejamento era direcionado para os programas prioritários do Ministério da Educação e a obrigatoriedade de elaborar projetos para essas áreas era, por sua vez, condição para contar com os recursos federais.

A isso se agrega a utilização intensiva do controle sobre a educação por meio do direcionamento de projetos específicos, com o atrelamento de financiamentos à fidelidade em sua execução.

\section{EDUCAÇÃO ESPECIAL EM RORAIMA}

Em 1974, assume o governo do território federal de Roraima o coronel Fernando Ramos Pereira, aviador amazonense que lá permanece até abril de 1979. É esse certamente um momento em que os olhos do governo militar volta-se à segurança e desenvolvimento dessa fronteira, transferindo recursos e equipes técnicas destinadas a efetivar a ocupação do território. Com ele traz um educador amazonense para condução da pasta da Educação, Aldo Gomes da Costa.

A expansão populacional, mediante o incentivo à migração de pessoas cujo perfil majoritário era de grupos sociais em situação de pobreza, para o trabalho na mineração ou agricultura, encontra uma região marcada pela precariedade das estruturas dos serviços de saúde, assistência e educação que nos permite supor a existência de uma população com índices elevados de deficiência desassistida, dado que ainda não se encontrava descrito nos censos demográficos ou escolares. 
O professor Aldo Gomes da Costa é referido em muitas de nossas entrevistas como um dirigente da educação que apoiou e estimulou a educação especial em Roraima. Em sua gestão é que as primeiras iniciativas se materializam e, em um segundo período no qual atuou na secretaria de educação, em 1991, tem um relevante registro de apoio ao desenvolvimento do atendimento educacional aos alunos com autismo.

Graduado em pedagogia, Aldo Costa, em entrevista, relata que participou, em 1970, de um seminário realizado em Brasília, na Universidade de Brasília (UnB), que teve como tônica a discussão dos princípios da reforma da educação que se projetava naquele momento e que veio a materializar-se na lei federal n. 5.692 de 1971. Em sua análise, mais que espaço de discussão, esse seminário constituiu-se em um processo de formação de quadros aptos a dar cumprimento integral às ações preconizadas na estruturação legal de interesse do governo militar que conduzia o país.

Kaufmann e Martins (2009, p. 246), em artigo no qual abordam de maneira comparativa "aspectos da história educativa da Argentina e do Brasil durante as últimas ditaduras militares do século XX", destacam o uso das "políticas repressivas culturais" como meio de alcance dos objetivos daqueles regimes. Eles salientam ainda que, para isso, os dirigentes militares brasileiros "efetivaram a reforma educacional do ensino superior, em 1968, e a reforma educacional da educação básica, em 1971" (idem, ibidem).

Nesse sentido, entendemos que a ação relatada pelo professor Aldo Costa é coerente com o momento vivido, em especial com a lógica de Segurança Nacional que permeava a política de instalação dos territórios federais:

A política educativa das ditaduras argentina e brasileira estabeleceu como princípio básico suas vinculações com a Doutrina de Segurança Nacional. [...] Perseguindo esses objetivos, concretizaram-se planos de formação docente, programas e propostas curriculares, conteúdos mínimos nacionais, propostas editoriais, livros didáticos de circulação nacional e regional que seguiam as pautas ministeriais oficiais. (idem, p. 243-244)

Atuando na Secretaria de Educação do Estado do Amazonas, com conhecimento e experiência de trabalho na região amazônica, o professor Aldo Costa, após a participação no referido seminário, passa a implantar em municípios do interior do Amazonas escolas de nível ginasial, um dos objetivos propostos na legislação de ensino em vigor, só se desligando dessa ação para assumir o desafio de gerenciar a educação no território federal de Roraima.

Como secretário de Educação, permanece atuando ao longo de todo o governo de Ramos Pereira, de abril de 1974 a abril de 1979. Em entrevista realizada em novembro de 2012, em Manaus, onde vive atualmente, o professor Aldo Costa destaca o fato de ter presenciado um momento histórico em que projetos e decisões, em especial nos territórios federais, vinham "de cima para baixo".

E é no período de 1974 a 1979 que encontramos as primeiras ações formais relacionadas ao processo de implantação de um setor de educação especial na perspectiva do cumprimento do preconizado pela legislação nacional. 
Registramos uma tentativa inicial de abertura de uma classe especial na primeira metade da década de 1970 - provavelmente em 1973 -, de duração efêmera, que conta com a titularidade da professora Clotilde Parima Rodrigues, mas a implantação efetiva dos serviços de educação especial ocorrerá apenas em 1976. Essa implantação encontra-se interligada à chegada a Roraima, entre os anos de 1974 e 1975, das professoras Carlota Maria Figueiredo Rodrigues e Célia Macedo Rodrigues.

Carlota Figueiredo era formada em magistério de nível médio, tinha realizado cursos na área da educação especial e trabalhado em uma APAE na cidade de Crato/CE. Célia vinha de Belém, estado do Pará, onde, além do curso de magistério, tinha frequentado o curso de Pós-Graduação para Professores de Deficientes Mentais, oferecido pelo Instituto de Educação do Pará até $1971{ }^{4}$ A esse grupo se agrega posteriormente a professora Clarice Soares Diniz, alfabetizadora cuja competência era destacada perante a comunidade.

Essa equipe, cuja carreira segue atrelada à educação especial até a aposentadoria, protagoniza o nascer das atividades nesse campo e sua expansão e transformação ao longo dos anos, em um processo simbiótico no qual, ao mesmo tempo em que construíam um sistema de educação especializada, constituíam-se também como profissionais da área - esta também em construção. Sua importância pode ser evidenciada em nosso trabalho ao verificar-se que esses protagonistas surgem como referência nos discursos de praticamente todos os entrevistados com os quais tivemos contato.

Três temas destacam-se nas entrevistas realizadas com essas "pioneiras": a progressiva constituição dos espaços destinados ao ensino especializado dos alunos com deficiência; a reflexão acerca do perfil dos alunos que então demandavam a existência da educação especial, sua posição na família e na sociedade; e o processo de tornar-se professor da educação especial na construção de uma formação técnica e de uma afinidade com a área.

Em termos práticos, para que os primeiros trabalhos de educação de pessoas com deficiência fossem desenvolvidos, foi necessária a realização de um processo de recrutamento ${ }^{5}$ nos bairros por crianças e adolescentes que apresentassem o perfil dos então classificados como excepcionais. Dessa forma, identificada uma criança

4 O Instituto de Educação do Pará é um dos mais antigos centros de formação de professores do Brasil, tendo sido fundado a 13 abril de 1871, e com forte tradição na área de formação docente para a educação especial. Esse curso teve sua oferta suspensa pela resolução n. 38 de 24 de junho de 1971, do Conselho Estadual de Educação do Pará.

5 Expressão presente em um relatório governamental da época, coerente com a concepção militar que permeava o período, mas que pode ser traduzido, na lógica atual, como um processo de "busca ativa". Na perspectiva da Vigilância Epidemiológica e Sanitária, o sentido de busca ativa é ir à procura de pessoas com o fim de uma "identificação sintomática" (Brasil, 2001). Vista em um sentido mais amplo, a busca ativa, de acordo com Lemke e Silva (2010, p. 285), pode ser entendida como "um movimento de ir à contracorrente do automatismo da demanda espontânea, no sentido de cartografar as necessidades de saúde para além dos agravos de notificação compulsória de determinado território”. 
que se supunha apresentar alguma deficiência, profissionais da própria equipe de professores deslocavam-se à residência das famílias e, constatada a situação de excepcionalidade, passava-se a um processo de esclarecimento aos pais e familiares quanto à necessidade de que a criança fosse encaminhada para a escola, nesse momento ainda em classes especialmente destinadas a esse fim.

Mesclam-se faixas etárias e condições de deficiência, com a predominância de alunos com deficiência auditiva e mental. Cumpre salientar a inexistência nesse período, em Roraima, de mecanismos formais de avaliação clínica, psicológica ou pedagógica das crianças, jovens ou adultos em condição de excepcionalidade, atendo-se os professores às indicações dadas pela aparência física ou comportamentos explicitamente manifestos.

Em uma das entrevistas que realizamos, questionada sobre como era feito inicialmente o diagnóstico que possibilitaria definir a condição de excepcionalidade dos que seriam candidatos a alunos da nascente educação especial, a professora Clarice Diniz, a quem dificilmente faltavam palavras, em um movimento corporal em que mimetiza um corpo disforme, retorcido, indica que o critério passava prioritariamente pelo impacto visual provocado pelo indivíduo.

Entendemos que esse critério levava a que apenas as crianças com maior profundidade de comprometimento fossem identificadas e, mais do que isso, conforme debatido em outro momento da entrevista, acabava por representar uma compreensão limitada da situação, por exemplo, de crianças cuja condição impactava mais diretamente no físico que no cognitivo, como aquelas com paralisia cerebral entendidas, nesse contexto, como crianças com pouca condição de desenvolvimento.

$O$ processo de trazer crianças para a sala de aula nem sempre se dava sem a resistência de pais ou familiares. $\mathrm{O}$ esconder crianças com deficiência no interior das casas, entendendo-as como um castigo divino ou como fonte de vergonha para as famílias, era algo comum. Mais que isso, predominava naquele momento a descrença na sua condição humana, a concepção de serem as pessoas com deficiência sem capacidade de se desenvolverem, aprenderem e participarem da vida social e comunitária. Na fala de Clarice Diniz:

Foi luta. Os pais deram mais trabalho do que as crianças. Porque ele tinha um filho lá... Deixa lá. É uma coisa. Como eles diziam...é uma coisa que não vai ter produção nenhuma. "Não é assim pai... ele tem alguma coisa boa". E quando eles foram vendo que as crianças estavam, principalmente na parte social, se desenvolvendo, aí eles começaram. "Olha... na casa... no bairro X tem uma criança". Nós íamos lá. E ficou "boca a boca”, sabe? "No bairro tal tem uma criança”. E nós íamos lá, conversávamos com o pai, e tínhamos que ter bom papo para derrubar.

A descrença na potencialidade de desenvolvimento e de aprendizagem das crianças com deficiência era corrente também entre os demais profissionais da educação, colegas atuantes nas escolas de ensino regular, que entendiam que essas crianças deveriam ocupar espaços próprios, apartados das crianças categorizadas como normais. Para esses outros profissionais, a escola não era lugar para aquele grupo que se avizinhava. Nos relatos das professoras pioneiras, a presença das 
crianças com deficiência nas escolas de ensino regular não foi alvo de acolhimento. Como afirma a professora Carlota Figueiredo, não houve:

Conscientização na comunidade escolar, que não conhecia aquele tipo de trabalho, então "xingavam" as crianças, chamavam de doido, e era aquela coisa toda [...] a escola não acolheu. Eles não ficavam satisfeitos. Achavam que aquele trabalho era inútil, que aquelas crianças não precisavam de atendimento e que deviam ficar nas suas casas.

O não fazer parte dos projetos da escola, nem em aspectos básicos, como o acesso ao lanche, o uso de quadras esportivas ou do pátio de recreio, é uma constante. No relato da professora Célia Macedo,

Ninguém aceitava; ninguém queria, nem o diretor. As crianças não podiam ficar na área fora da sala de aula, nem no pátio da escola. Merendavam dentro da sala. Tudo era feito dentro da sala.

Esse mal-estar em relação à presença daqueles "diferentes" transpassa todo o período de circulação das crianças nas escolas de ensino regular e irá direcionar a busca por alternativas várias até que se chegue à construção de uma área própria, especificamente direcionada à educação de pessoas com deficiência. Não havia mais, entretanto, meios de se manter essas pessoas fora dos espaços sociais. Na síntese da professora Clotilde Rodrigues: "as crianças cada vez chegando mais, que ninguém sabia que tinha tanto aluno deficiente. Mas tinha!”

\section{ESPAÇOS DA EDUCAÇÃO ESPECIAL NO TERRITÓRIO FEDERAL}

Ao final de 1977, a Escola Monteiro Lobato, que havia dois anos sediava as ações da educação especial, entra em reforma. Os alunos do ensino regular são redistribuídos em escolas próximas. Os aproximadamente vinte alunos da classe especial não encontram a mesma disponibilidade para seu atendimento. Assim, perde-se um espaço que, embora não lhe fosse acolhedor, havia sido o disponível até aquele momento.

A alternativa para que não ocorresse a interrupção das ações da educação especial foi a locação, em 1978, de um imóvel residencial. Embora essa nova estratégia pudesse trazer em si a possibilidade de organização de espaços mais ajustados às necessidades dos alunos, tende a fortalecer uma lógica de segregação, de afastamento do contexto da educação oferecida às crianças tidas como clientela do ensino regular. Além disso, o deslocamento para imóveis alugados não concretiza a adequação real dos espaços às necessidades dos alunos, uma vez que os ajustes e reformas nem sempre se materializam a contento, dado o volume de investimento que seria necessário para a conversão de residências em escolas.

A questão da expansão de clientela e de espaços veio atrelada à oferta de transporte próprio para os alunos da educação especial. Esse transporte, inicialmente destinado para a locomoção da equipe que realizava o recrutamento de crianças nas casas, acabou por ser mantido para o uso cotidiano também do alunado. Embora 
considerado fundamental para a existência dos serviços, realizava-se de maneira irregular e descontínua. No destaque dado ao impacto provocado pela não regularidade do transporte para o desenvolvimento das atividades na chamada escolinha, conta-nos a professora Carlota Figueiredo:

Sempre foi assim, com muito paternalismo, a educação especial. O governo cedia o transporte, ia pegar em casa, ia deixar. No dia que o carro quebrava, aparecia algum problema, poderia passar uma semana, um mês, dois, sem aquela criança frequentar aquela escola. [...] ou o carro do governo ia buscar, ou ficava sem atendimento. Nada acontecia.

A questão do "paternalismo" aqui citada, que reaparece em outros momentos, em outros relatos e em outras práticas, é sem dúvida um dos temas que nos mobilizaram na necessidade de construção de maiores reflexões para a compreensão desses processos.

Quando foi criada a educação especial, era com muito paternalismo; se a gente queria que eles participassem de um evento como o Sete de Setembro, naquela época era o Treze de Setembro, o aniversário do território, que era um desfile muito bonito, então a gente queria fazer uma apresentação das crianças, levava as crianças para dormir na escola, para de manhã a gente arrumar, para na hora do desfile estarem arrumadinhos. Porque, se deixasse em casa, os pais ignoravam que tinha que fazer aquilo. Isso para você ver que assistencialismo. A gente assumia as responsabilidades da família. Para levar ao médico, o professor, a diretora levava, porque todo mundo se empenhava naquele trabalho.

Estamos cientes do caráter dúbio apresentado pelo termo paternalismo como apontado por Thompson (2011, p. 32), ao definir que esse,

Tende a apresentar um modelo da ordem social visto de cima. Tem implicações de calor humano e relações próximas que subentendem noções de valor. Confunde o real e o ideal. Isso não significa que o termo deva ser abandonado por ser totalmente inútil. Tem tanto ou tão pouco valor quanto outros termos generalizantes - autoritário democrático ou igualitário - que em si e sem adições substanciais não podem ser empregados para caracterizar um sistema de relações sociais.

Compartilhamos aqui o entendimento de Thompson $(2002,2011)$ de que o paternalismo funciona normalmente como uma forma de "seguro social" no intuito de manutenção de uma determinada "ordem social" por meio do domínio que se estabelece nas relações de dependência. Entretanto, ao mesmo tempo em que olhamos essas atitudes tidas como "paternalistas", como incentivo a uma acomodação, como "atos calculados de apaziguamento de classe", precisamos considerar também que "o que é (visto de cima) um 'ato de doação' é (a partir de baixo) um 'ato de conquista”' (Thompson, 2011, p. 68-69). 
Nesse sentido, no entendimento desses familiares e dos alunos adultos com os quais tivemos contato, a existência de uma estrutura de transporte, alimentação e apoios clínicos, entre outros serviços que podem ser lidos como ação paternalista, é compreendida como uma conquista das pessoas com deficiência que, incorporadas à rotina familiar como direito, passam a compor parte do universo de vida daqueles sujeitos. Isso nos leva à compreensão até de que o não enviar à escola os alunos quando da inoperância do transporte possa ser também compreendido como uma demonstração da resistência que seria aposta à eventual possibilidade de encerramento desse tipo de serviço.

E, no que diz respeito ao educacional, que práticas pedagógicas eram desenvolvidas com esssas crianças que chegavam à escola? Pelo que nos foi possível inferir nos discursos que emergiram das entrevistas realizadas com as professoras responsáveis, eram atividades típicas da educação pré-escolar praticada naquele momento histórico, especificamente voltado às atividades de preparação para alfabetização e alfabetização em si, ou que se direcionavam ao desenvolvimento de habilidades manuais, quando do fracasso das tentativas de escolarização convencional. $\mathrm{Na}$ fala da professora Carlota Figueiredo:

A gente tentava alfabetizar aquelas crianças. Quando a gente via que não tinha como alfabetizar, eles não aprendiam, porque tinha uns mesmo que não aprendiam, a gente começava com trabalhos manuais, tentando fazer uma socialização, ensinando trabalhos manuais para que eles pudessem ter uma vida própria, para ajudar em casa, ajudar os pais e aprender alguma profissão.

Em relação à direção das atividades desenvolvidas nesse período de utilização de casas alugadas, em um primeiro momento, segundo nos informa a professora Clarice Diniz,

Não tínhamos uma equipe multidisciplinar. Não tinha psicólogo, não tinha assistente social, não tinha nada. Ia alguém da [Secretaria de] Educação uma vez por semana lá nessa escola, para saber como os meninos estavam. Tinha um carro que rodávamos com revezamento para pegar os alunos nas casas. Nós íamos pegar esses meninos em casa. A matrícula era feita por nós, porque não tinha diretora. Aí foi estruturando... quando veio aqui para perto da Assembleia.

E é nesse processo de instalação da escolinha em casas alugadas, fora das estruturas escolares já existentes, com a presença de estagiários da Universidade Federal de Santa Maria (UFSM), que se deslocavam a Roraima no âmbito do Projeto Rondon, que se vai consolidando a perspectiva de um serviço especializado em educação especial e a ideia de constituição de equipes de atendimento terapêutico. Ao longo dos anos, vemos estabelecer-se uma redução do foco na perspectiva educacional, e a lógica de atribuição de importância às terapias de natureza clínica começa a ser incorporada ao cotidiano dos professores. 


\section{O CONTEXTO DOS ANOS 1980}

A situação econômica por que passa o país, no final dos anos de 1970 e início da década de 1980, afetada pela crise internacional do petróleo, é de intensa instabilidade econômica, com alto índice inflacionário e comprometimento no desempenho das finanças governamentais. Apesar disso, há registros do apoio recorrente do Ministério do Interior aos governos dos territórios, e o desenvolvimento dos demais estados da região amazônica apresenta-se como prioridade do governo federal, nesse momento sob o domínio das Forças Armadas.

Em face disso, Roraima passa, de certa forma, ao largo da crise financeira que afeta o restante do país, tornando-se um dos pontos de escape das populações do centro-sul e do nordeste em busca de melhores condições de vida, terras, emprego e renda. Com uma economia centrada em recursos advindos de receitas do governo federal, em seu interesse de ocupar os vastos territórios de fronteira, vive-se uma expansão populacional sem precedentes. Mas qual a presença e a relevância da educação especial nesse contexto?

Como indicativo da presença forte e do crescimento da representatividade do trabalho em educação especial na comunidade, três curiosos documentos foram encontrados entre os elementos de rotina na documentação do Centro de Educação Especial: dois vindos da Câmara Municipal de Boa Vista, sendo um deles de dezembro de 1980, informando a doação de máquina de costura "por reconhecer ser uma das classes mais carentes, e por julgar venha a ser útil ao aprendizado dos alunos desta Escola”; e o outro um ofício, de 12 de setembro de 1983: uma Moção de Aplauso à Equipe de Trabalho salientando a "tão nobre dedicação a esta causa sublime que são as vossas mãos e corações estendidos aos Excepcionais de Roraima", rogando ainda que "Deus os auxilie nesta difícil missão".

A perspectiva missionária, posicionando um trabalho técnico que deveria ser parte do cotidiano de ação dos órgãos públicos como benemerência abnegada, como "causa" a exigir a generosidade e dedicação de um grupo peculiar, manifesta-se intensamente nesses documentos emitidos por pessoas que respondem como representantes eleitos da comunidade. Associa-se ainda a deficiência à carência de recursos de subsistência que justificaria a necessidade de fornecimento de equipamentos de profissionalização. Em que pese a pertinência de que se ofereça também a profissionalização, há aí um reforço ao desvio do foco educacional propriamente dito, que sinaliza a imagem que a coletividade cultivava desse trabalho.

O terceiro documento que nos pareceu curioso é um ofício circular assinado pela presidente da Comissão de Moral e Civismo requisitando o envio de documentos, a saber: Cronograma de Atividades de 1981; Plano de curso dos professores das disciplinas Educação Moral e Cívica (EMC) e Organização Social e Política Brasileira (OSPB); regimento do CCE (sigla que não é explicitada no documento) e Código de Honra (sic) e curriculum vitae dos professores de EMC e OSPB. São os rastros explicitados das ações de uma ditadura militar "incluindo" a todos em seus princípios de "formar, cultivar e disciplinar" (Kaufmann; Martins, 2009, p. 246).

Outro momento que compõe o cotidiano da Escola de Educação Especial é a realização da Semana Nacional da Criança Excepcional decretada pelo então 
presidente Castello Branco, em 1964. Nos documentos aos quais tivemos acesso, a Semana do Excepcional é parte das atividades rotineiras da equipe da educação especial com pequenas variações de data a cada ano. Essas semanas são demarcadas por programações que se diversificam ao longo dos anos, mas guardam entre si algumas peculiaridades:

a) Presença de um discurso missionário e religioso, em alguns casos até mesmo com a realização, no interior do conjunto da programação oficial, de missas em igrejas católicas;

b) Manhãs e tardes de lazer oferecidas por outras escolas e realizadas nas escolas que se integram ao trabalho, inclusive as Escolas de Formação de Professores e Escola Agrotécnica, com atividades que envolvem a participação de professores e alunos que recebem e realizam programações de lazer e cultura voltadas às crianças da Escola de Educação Especial;

c) Atividades de esporte, cultura e lazer oferecidas por instituições como o Exército, Polícia Militar e a coordenação de esportes da secretaria de educação, por exemplo;

d) Sessões de filmes na sala de cinema da cidade de Boa Vista.

O material de divulgação da Semana Nacional da Criança Excepcional traz, além da programação de atividades, slogans e palavras de ordem de sensibilização quanto às questões da deficiência, com discursos de forte apelo emocional à comunidade, em uma perspectiva de solidariedade e permeado por uma ótica de benemerência e humanismo cristão.

No conjunto desse esforço de institucionalização da educação especial no território, vemos o movimento do estabelecimento de uma normatização legal para os serviços, expresso na homologação da resolução n. 15/1978 do Conselho Territorial de Educação de Roraima (CTE) que fixa normas gerais para a Educação Especial no Território Federal de Roraima. Essa normatização no interior das unidades federadas era, provavelmente, alvo de atenção e controle por parte do governo central. Jannuzzi (2004, p. 160) salienta que "em 1977, das 25 unidades federadas, em apenas 11 os conselhos estaduais haviam fixado normas a ela referentes".

A resolução n. 15/1978, vindo a reboque de um processo de trabalho já em andamento, estabelece critérios gerais para matrícula e atendimento dos excepcionais em consonância com a legislação nacional vigente àquele momento, estabelecendo, por exemplo, no artigo 15, a competência da Secretaria de Educação e Cultura do Território de "implantar gradativamente o Ensino Especial no Território". Interessante o parágrafo único que acompanha esse artigo, apontando que a mesma secretaria "apoiará qualquer iniciativa privada que de acordo com a legislação vigente se proponha a ministrar este tipo de ensino”, fato que, na prática, nunca veio a se efetivar.

Nos anos seguintes, dois outros pareceres do CTE se seguiriam: o parecer n. 48/1981 aprovando a realização de um amplo Programa de Educação Especial firmado em parceria com o CENESP, com dotação orçamentária destinada à capacitação de recursos humanos e expansão e melhoria da rede física com o objetivo 
de oportunizar a melhoria do atendimento às chamadas pessoas deficientes por meio da educação especial.

Outro parecer do CTE viria apenas em 1984, que em seu item intitulado "Histórico" propõe "estabelecer as linhas gerais sobre o funcionamento das Classes Especiais em estabelecimentos comuns de ensino, para crianças e adolescentes excepcionais", prática que já se vinha efetivando desde 1981 (Roraima, 1984).

$\mathrm{O}$ vínculo administrativo da escolinha é com a Coordenação de Educação Especial do Departamento de Educação Especial e Assistência ao Educando da Secretaria de Educação. Parte significativa do financiamento é do âmbito do MEC e de recursos destinados à educação, mas ações de habilitação e reabilitação do âmbito médico começam a ser incorporados aos trabalhos, seja pela ação dos estagiários e rondonistas da UFSM, seja pelas primeiras contratações de especialistas e da efetivação de convênios nessa perspectiva.

Um dos convênios cujos contratos localizamos efetivou-se com a Legião Brasileira de Assistência (LBA), que possuía uma superintendência instalada no território federal de Roraima.

$\mathrm{Na}$ análise de planilhas orçamentárias da Secretaria de Educação e Cultura do Governo Territorial, é possível verificar que esse organismo realiza investimentos em três áreas específicas nos primeiros anos da década de 1980: a educação pré-escolar, a assistência comunitária e a educação especial. No campo da educação especial, um convênio realizado ao final de 1981 com a Secretaria de Educação e Cultura de Roraima tinha por objeto a prestação de assistência de reabilitação ao excepcional, inicialmente a atingir trinta alunos.

Esse convênio objetivava "assegurar assistência de reabilitação" pela oferta de serviços especializados de diagnóstico e tratamento, bem como garantir que a secretaria efetivasse "adaptação às normas vigentes do Programa de Assistência aos Excepcionais da LBA”. No destaque que dá para a sua conceituação de diagnóstico, no parágrafo único, cláusula primeira do referido contrato, temos que:

Constitui diagnóstico a avaliação das condições físicas, mentais e psicossociais do excepcional, formulado por equipe interprofissional, visando a estabelecer prognóstico, programação terapêutica e tratamento de reabilitação, processo que garante ao excepcional a aplicação de recursos integrados de tratamento médico, psicológico e social.

Esse contrato é renovado em outubro de 1982, agora com a perspectiva de atendimento a cento e vinte crianças, mantida a perspectiva de "atendimento" terapêutico e clínico. Jannuzzi (2004, p. 159-160) trata das relações entre a LBA e o CENESP salientando a oficialização da:

Portaria interministerial n. 477, de agosto de 1978, do MEC e do Ministério da Previdência e Assistência Social (MPAS), estabelecendo ação integrada dos dois órgãos. Nessa portaria o diagnóstico seria feito pela LBA, órgão ligado ao MPAS, ou por serviços médicos psicossociais ou educacionais da comunidade para o encaminhamento ao CENESP. O resultado foi o crescimento dos serviços de reabilitação sem o prosseguimento educacional. 
Mazzotta (2001, p. 74, grifos do original), referindo-se a essa mesma ação, mas já apresentando uma análise das consequências da interlocução que se efetiva nesses convênios, destaca:

A despeito da delimitação de campos de atuação do Ministério da Educação e Cultura (CENESP) e do Ministério da Previdência e Assistência Social (LBA e INPS), atribuindo-se ao primeiro o atendimento educacional e ao segundo o atendimento médico-social e a reabilitação, há em ambos um traço comum que os situa como o campo de ação preventiva e corretiva.

Roraima, como território e, portanto, espaço privilegiado de implantação e implementação das políticas de interesse do governo central, vivencia esses reflexos de maneira intensa.

Paralelamente à definição de um espaço específico para o atendimento aos educandos com deficiência, vemos a chegada e paulatina ampliação de um perfil de atendimento com características de ação cuidadora, com a mescla de serviços de saúde e nutrição no interior da escola. Há que se destacar, entretanto, que essa não era uma especificidade da educação especial, mas práticas que se disseminavam também no ensino regular acompanhando a lógica do disciplinamento corporal típica das concepções militaristas de educação.

As bases para a constituição dos serviços dentro dessa lógica começam a dar-se também por meio de outras ações, como os cursos de formação promovidos pelo CENESP. Sem dúvida era parte do processo formativo dos técnicos e docentes de Roraima esse perfil de construção de um olhar medicalizante e biologizante com foco na perspectiva clínico-terapêutica para o desenvolvimento das ações pedagógicas.

\section{NASCEM OS CENTROS DE EDUCAÇÃO ESPECIAL DE RORAIMA}

O território, até 1982, tem apenas dois municípios instalados: Boa Vista e Caracaraí. Esses dois municípios participam ativamente das atividades propostas em todo o país para o Ano Internacional da Pessoa Deficiente realizado em 1981. A professora Maria Mirna Souto Maior Sarah, que havia representado Roraima nas reuniões da Comissão Nacional do Ano Internacional do Deficiente, realizadas no CENESP, no Rio de Janeiro nos períodos de 30 e 31 de março e de 27 a 30 de abril, coordena a execução dessas ações e nos relata:

Em 1981, quando foi o Ano Internacional da Pessoa Deficiente, o Ottomar [de Souza Pinto], governador, a LBA, etc. e tal, monitorou isso tudo e fizeram aqui a programação. Conseguiram levar uma porção de pessoas, e a Hermana [Duarte Reis], a primeira-dama de Caracaraí, ela apoiou demais... E ela era de sair de casa em casa, não era só interesse político não. Aí veio um pedido. Veio uma moça do Paraná, uma síndrome de Down que tinha estudado fora. Levantou essa criança e pediu que queria escola, que ela queria estudar. Era uma menina de uns 15 anos e com as dificuldades dela, ela conseguiu se expressar 
bem. Ottomar, o pessoal que estava lá todo, ele virou e falou; "Professora, agiliza isso aí”. Me chamou e mandou agilizar. O evento era para se falar o que se queria conquistar. Foram autoridades daqui, secretários, etc. e tal, e de lá também.

Caracaraí em 1980 era um município com 12.309 habitantes, considerando suas áreas rural e urbana. Ainda não haviam sido construídas as pontes de acesso. Cada ida àquele município implicava um trajeto de pelo menos seis horas em estrada de terra com travessia de balsa em condições precárias. A infraestrutura urbana também era bastante deficitária, embora fosse aquele o município onde se dava a parada final das embarcações provenientes de Manaus ou do sul do território pelo rio Branco.

A participação que viabilizou o projeto foi da Prefeitura Municipal de Caracaraí, que aluga uma casa onde se instala uma unidade da educação especial naquele município:

Com o apoio da primeira-dama e do prefeito, o Dr. Antonio [Reis]. Alugaram um local e nós fomos ver o local, e eu fiquei por lá nem sei quanto tempo para localizar, e ficou que nem nós começamos aqui. Uma casa alugada... E tinha muita gente que a primeira-dama achou. [...] Depois eles construíram o Centro. Lá a prefeitura assumiu mesmo, era uma parceira que a gente podia contar com eles, e construíram o prédio. Aí ia nas escolas, o mesmo trabalho que a gente fez aqui, divulgando nas escolas, eles fizeram lá. (Mirna Souto Maior Sarah)

O Centro de Educação Especial de Caracaraí, atualmente Centro de Educação Especial "Denise Messias Santos", é inaugurado em 12 de março de 1982. É no nascimento do Centro de Educação Especial de Caracaraí que identificamos o primeiro movimento vindo da comunidade de reinvindicação de um serviço na área. Mesmo que ainda não representando um movimento social organizado, a manifestação de uma cidadã posta em um momento politicamente adequado disparou uma ação relevante para toda a coletividade.

Nos anos seguintes, a chegada de profissionais especializados e a busca de uma fundamentação técnica das ações vão acentuando a lógica de separação das crianças nos espaços por categoria de deficiência, que já havia sido iniciada na distribuição de salas de aula nas casas alugadas. Passa-se a concentrar ali educandos com deficiência mental e a deslocar os que apresentavam deficiências sensoriais para espaços diferenciados.

No caso dos surdos ou com deficiência auditiva, o número expressivo de alunos leva inicialmente à ampliação no volume de classes específicas para esse perfil e, na sequência, à implantação, no ano de 1989, da Escola de Audiocomunicação, que virá a ser instalada também em uma casa adaptada e posteriormente em prédio próprio.

No caso dos alunos cegos e com deficiência visual, em menor número, tivemos sua saída em 1989 para uma escola regular e a permanência, nos anos de 1990, em espaços cedidos em escolas regulares, com mudanças várias a critério dos interesses dos gestores de cada momento. 
Começa-se também a trazer com maior precocidade para o atendimento clínico e educacional as crianças em situação de risco ou com deficiência já detectada, iniciando o trabalho de estimulação precoce com os alunos em idade pré-escolar $\mathrm{e}$, mais adiante, com bebês.

Algumas noções sobre as diferenças entre os alunos começam a se apresentar na medida em que se agregam conhecimentos específicos da educação especial aos saberes pedagógicos dos professores. É o caso dos alunos com paralisia cerebral. Com a qualificação dos professores é que se estabelece a noção de que estes, mesmo com limites em sua mobilidade e expressão, apresentavam capacidades cognitivas a serem trabalhadas. Na fala de Clarice Diniz:

Foi aparecendo paralisado cerebral que a gente misturava lá com os "mentais", porque até então ninguém tinha noção de que eles tinham inteligência. Para você ver como são as coisas. Porque pega uma equipe de professor leigo, que até então só sabia trabalhar com crianças ditas normais. E pega e põe para trabalhar...

O volume de alunos, que em meados dos anos de 1980 gira em torno de um pouco mais de uma centena no Centro de Educação Especial de Boa Vista e de trinta alunos no Centro de Educação Especial de Caracaraí, passa a ser observado em suas especificidades. Caminhos mais objetivos para o desenvolvimento dos alunos de faixa etária mais elevada começam a ser construídos na forma de oficinas pedagógicas, coadunando-se com as políticas nacionais vigentes e as diretrizes do CENESP, que, conforme destacado em Pires (1974, p. 31), recomendam:

Os alunos deficientes atendidos em oficinas pedagógicas deverão ter oportunidades de adquirir autossuficiência e competência social através da educação geral e formação ocupacional, nessas instituições serão desenvolvidos nos alunos atitudes e hábitos de trabalho, habilidades e aptidões e, como etapa final, haverá a utilização da preparação recebida pelos deficientes no seu encaminhamento para o trabalho.

A professora Maria Neusa de Lima Pereira, que atua como supervisora nos anos iniciais do Centro de Educação Especial, destaca a existência de salas destinadas ao desenvolvimento de psicomotricidade, sala de música, sala de atividades de vida diária (AVD), salas de aula e espaços para as oficinas pedagógicas, além do refeitório. Apresenta a preocupação e o comprometimento de toda a equipe no desenvolvimento e produção de materiais didáticos, como jogos, fichas e planilhas de acompanhamento.

Crescem as instalações de classes especiais nas escolas de ensino regular. Uma das pioneiras nesse processo é a professora Maria Neusa de Lima Pereira, que em um trecho de seu relato aponta para uma questão que se irá repetir ao longo do acompanhamento de outros processos de criação da educação especial: a instalação de classes nas escolas regulares dar-se-á na forma de um processo interno de segregação em que os alunos são instalados em áreas improvisadas, pequenos espaços de fundo de corredor, vãos de escadas, enfim, espaços em sua definição "escondidinhos". 
$\mathrm{Na}$ época eles chamavam de classe especial, era o processo de Integração [...] Ficava segregado, na verdade, porque ficava no canto mais distante, mais escondidinho, e a gente ficava com aquelas crianças ali, dizendo que estava fazendo Integração. Eu não era conformada com aquilo, não gostei da situação, não acreditava naquela Integração, naquele projeto.

Em alguns casos, na fala dos professores, esses alunos terão horários diferenciados para lanche, recreio e até "privilégios" no acesso aos acervos das bibliotecas e atividades de educação física que lhes possibilitassem desenvolver todas as atividades dentro da própria sala de aula, sem contato com os demais alunos da escola.

A equipe de trabalho atua integrada à Secretaria de Educação e Cultura, em interlocução com os demais serviços, participando intensamente dos processos de formação oferecidos pelo CENESP, estando o conjunto de atividades que veio sendo colocado em prática no território em estrita consonância com os princípios básicos que direcionavam a atuação daquele órgão.

No elenco dos serviços, na lógica de estruturação das atividades, na sequência de implantação e encaminhamento das formações de equipes, é fortemente perceptível o caráter de campo de aplicação de políticas que o território federal representava, no intuito de constituir-se em espaço onde tudo era novo, o campo "limpo", sem ações a serem reformuladas. Apenas um espaço em que o vazio de ações especializadas em âmbito privado possibilitava aos órgãos públicos direcionar todo o trabalho de maneira mais aproximada em relação ao pensado e proposto pelos técnicos atuantes no poder central, como um "laboratório" experimental de políticas, isento de resistências e oposições.

\section{PRIVATIZAR... UM CAMINHO EM EDUCAÇÃO ESPECIAL?}

$\mathrm{Na}$ lógica de busca de replicar o modelo que se disseminava no restante do Brasil, vários são os relatos que se referem à intenção, não concretizada, de criação de uma APAE em Roraima. Em um deles nos conta a professora Carlota Figueiredo:

Foi na época do governo do doutor Getúlio Cruz. A esposa dele, a primeira-dama, dona Nazaré Cruz, tentou criar uma APAE, lá pelo palácio do governo. [...] Como que vai criar APAE, se o governo dá total cobertura em tudo? No meu modo de pensar, porque o governo toda a vida foi quem abraçou. A prefeitura abraçou. Não tem APAE, não tem Pestalozzi, não tem nada. E eu acho, no meu modo de ver, aqui funcionou bem, com o estado assumindo tudo, até onde eu fiquei [...] E eu não sei por que queriam fundar a APAE. Um dia eu perguntei: "Por que querem fundar a APAE? O que está acontecendo?" Para tirar a responsabilidade do estado! Não! Deixa com o estado. Está é bom: o professor é do estado, carro do estado, merenda do estado, motorista do estado, o que é que vocês querem mais? Tirar uma responsabilidade que está no estado para abraçar e depois não ir adiante e morrer? 
E, retomando aqui um alerta que nos faz Thompson de que aquilo que "visto de cima" é considerado paternalismo, "visto de baixo" pode ser considerado uma conquista, um alcance de direitos. Um dos pais, participantes em nosso processo de entrevistas, destaca:

Eu nunca fui a favor da APAE. A conclusão que eu cheguei: o nível de participação é muito baixo, o nível de esclarecimento dos pais é muito baixo. [...] A APAE, quando ela foi criada, a realidade era outra, então, na minha visão e tentando justificar a minha opinião: se você trouxer, "eu boto" a APAE aqui, eu estarei canalizando a minha força para fazer um Centro de Estimulação Precoce privado, e o governo que tem o dever de fazer está lá gastando também. Por que eu não canalizo a minha força para fazer o Centro de Estimulação público funcionar? Eu tenho o direito! É o meu dinheiro que está lá [...]. Antigamente, com a ausência do estado, a APAE teve a importância dela. Eu tenho medo do terceirizar.

Esse processo da realização da educação especial no âmbito dos serviços públicos educacionais marca o início e a estruturação desse campo no território federal de Roraima e permanece, na atualidade, com essas características.

Em nossa pesquisa, concluímos que o isolamento geográfico, a ocupação tardia e a posição fronteiriça favoreceram que Roraima se constituísse em campo de aplicação das políticas e propostas prioritárias implantadas na reforma educacional projetada pelo regime militar. Dessa forma, ao analisar como a implantação dos serviços de educação especial se deu, evidenciamos o teor dos procedimentos propostos no planejamento técnico da equipe que assessorava os dirigentes militares, com práticas respaldadas em posturas educacionais compreendidas como tecnicistas.

No território federal de Roraima, encontrou-se um terreno fértil e aberto à testagem e à implantação de projetos prioritários assumidos localmente como práticas positivas pelos professores e demais profissionais envolvidos, não havendo resistência da coletividade diante da inexistência de movimentos sociais organizados ou de instituições filantrópicas que agregassem outros interesses (como acesso a recursos e financiamentos) aos processos educacionais.

Dessa forma, "nasce" um atendimento a pessoas com deficiência com viés efetivamente educacional, integrada aos órgãos gestores da educação, com menor ênfase de assistência social ou de atividade clínico-terapêutica que se encontrava em expansão nos demais estados brasileiros.

Posteriormente, as ações de capacitação oferecidas pelo CENESP, que assumiam como seus ministrantes os profissionais em atuação em instituições clínico-terapêuticas e assistenciais privadas, trouxeram impactos na concepção de sujeitos que então orientavam as atividades educacionais, levando à fragmentação destes pelas especificidades de suas deficiências.

Ainda assim, considerando-se que o ponto de partida da atenção às pessoas com deficiência era o sistema de ensino regular, foram mantidos alguns focos que entendemos serem relevantes: educação como eixo prioritário das ações; uso dos recursos públicos de educação no próprio sistema público, e não em instituições 
privadas; interlocução permanente com as escolas e seus órgãos de assessoramento, enfim, a construção de uma perspectiva de entendimento das pessoas com deficiência como "sujeitos da educação", e não apenas como "clientela" da saúde ou assistência social.

\section{REFERÊNCIAS}

Bastos, M.H. C. Pense globalmente, pesquise localmente? Em busca de uma mediação para a escrita da história da educação. In: MendonçA, A. W. et al. (Orgs.). História da educação: desafios teóricos e empíricos. Niterói: Editora da Universidade Federal Fluminense, 2009. p. 66-91.

Brasil. Presidência da República. Lei n. 4.024, de 20 de dezembro de 1961. Fixa as Diretrizes e Bases da Educação Nacional. Diário Oficial da União, Brasília, DF, 27 dez. 1961.

Presidência da República. Decreto n. 54.188, de 24 de agosto de 1964. Institui a semana Nacional da Criança Excepcional. Diário Oficial da União, Brasília, DF, 24 ago. 1964. Seção 1, p.7.532.

.Presidência da República. Lei n.5.692, de 11 de agosto de 1971. Fixa as Diretrizes e Bases para o ensino de $1^{\circ}$ e $2^{\circ}$ graus, e dá outras providências. Diário Oficial da União, Brasília, DF, 12 ago. 1971.

. Conselho Federal de Educação. Parecer CFE n. 848/72 sobre educação de excepcionais, de 10 de agosto de 1972. Brasília, DF, 1972.

Presidência da República. Decreto n. 72.425, de 3 de julho de 1973. Cria o Centro Nacional de Educação Especial (CENESP), e dá outras providências. Diário Oficial da União, Brasília, DF, 4 jul. 1973. Seção 1, p. 6.426.

. Ministério da Saúde. Organização Pan-Americana da Saúde no Brasil. Doenças relacionadas ao trabalho: manual de procedimentos para os serviços de saúde. (Organização: Elizabeth Costa Dias; Colaboração: Idelberto Muniz Almeida). Brasília: Ministério da Saúde do Brasil, 2001.

BuEno, J. G. S. Educação especial brasileira: integração/segregação do aluno diferente. 2. ed. São Paulo: EDUC, 2004.

FARIA Filho, L. M. História da educação e história regional: experiências, dúvidas e perspectivas. In: MendonçA, A. W. et al. (Orgs.). História da educação: desafios teóricos e empíricos. Niterói: Editora da Universidade Federal Fluminense, 2009. p. 57-65.

Jannuzzi, G. A luta pela educação do deficiente mental no Brasil. São Paulo: Cortez, 1985. A educação do deficiente no Brasil: dos primórdios ao início do século XXI. Campinas: Autores Associados, 2004.

Kaufmann, C.; Martins, M. C. Ditaduras militares argentina e brasileira: colaborações culturais em educação na década de 1970 do século XX. In: Vidal, D. G.; Ascolani, A. (Orgs.). Reformas educativas no Brasil e na Argentina: ensaios de história comparada da educação (1820-2000). São Paulo: Cortez, 2009. 
Lemke, R. A.; Silva, R. A. N. A busca ativa como princípio político das práticas de cuidado no território. Revista Estudos e Pesquisas em Psicologia, Rio de Janeiro: UERJ, ano 10, n. 1, p. 281-295, 2010. Disponível em: <www.revispsi.uerj.br/v10n1/artigos/ pdf/v10n1a18.pdf>. Acesso em: 15 ago. 2012.

Mazzotta, M. J. S. Educação especial no Brasil: história e políticas públicas. 3. ed. São Paulo: Cortez, 2001.

Onu - Organização das Nações Unidas. Assembleia Geral das Nações Unidas. Declaração dos Direitos do Deficiente Mental. ONU: 22 dez. 1971.

Pires, N. Educação especial em foco. Rio de Janeiro: Centro de Pesquisas Educacionais, 1974.

Ramos, L. C. Educação: memórias e reflexões. Boa Vista: Advanced. 2007.

Roraima. Secretaria de Educação e Cultura. Conselho Territorial de Educação. Parecer CTE n. 17/1978. Fixa normas gerais para a educação no Território Federal de Roraima. Boa Vista: 9 ago. 1978.

Secretaria de Educação e Cultura. Conselho Territorial de Educação. Parecer CTE n. 48/1981. Aprova Programa de Educação Especial do CENESP/MEC/SEC que tem por objeto a capacitação de recursos humanos e a expansão e melhoria da rede física. Boa Vista: 23 dez. 1981.

Secretaria de Educação e Cultura. Conselho Territorial de Educação. Parecer CTE n. 29/1984. Traz instruções sobre o funcionamento de classes especiais. Boa Vista: 2 ago. 1984.

Santos, N. P. D. Políticas públicas, economia e poder: o estado de Roraima entre 1970 e 2000. 2004. 271f. Tese (Doutorado em Desenvolvimento Sustentável do Trópico Úmido) - Universidade Federal do Pará, Belém, 2004.

Saviani, D. História das ideias pedagógicas no Brasil. Campinas: Autores Associados, 2010. Thompson, E. P. A miséria da teoria. Rio de Janeiro: Zahar Editores, 1981.

Costumes em comum: estudos sobre a cultura popular tradicional. São Paulo: Companhia das Letras, 2011.

\section{SOBRE A AUTORA}

Maria Edith Romano Siems-Marcondes é doutora em educação especial pela Universidade Federal de São Carlos (UFSCar). É professora da Universidade Federal de Roraima (UFRR).

E-mail: edithromanos@hotmail.com 